\title{
Pravastatin inhibits fibrinogen- and FDP-induced inflammatory response via reducing the production of IL-6, TNF- $\alpha$ and iNOS in vascular smooth muscle cells
}

\author{
PEIPEI LU, JUNTIAN LIU and XIAOMING PANG \\ Department of Pharmacology, Xi'an Jiaotong University School of Medicine, Xi'an, Shaanxi 710061, P.R. China
}

Received October 17, 2014; Accepted July 10, 2015

DOI: $10.3892 / \mathrm{mmr} .2015 .4149$

\begin{abstract}
Atherosclerosis is a chronic inflammatory response of the arterial wall to pro-atherosclerotic factors. As an inflammatory marker, fibrinogen directly participates in the pathogenesis of atherosclerosis. Our previous study demonstrated that fibrinogen and fibrin degradation products (FDP) produce a pro-inflammatory effect on vascular smooth muscle cells (VSMCs) through inducing the production of interleukin-6 (IL-6), tumor necrosis factor- $\alpha$ (TNF- $\alpha$ ) and inducible nitric oxide synthase (iNOS). In the present study, the effects of pravastatin on fibrinogen- and FDP-induced expression of IL-6, TNF- $\alpha$ and iNOS were observed in VSMCs. The results showed that pravastatin dose-dependently inhibited fibrinogen- and FDP-stimulated expression of IL-6, TNF- $\alpha$ and iNOS in VSMCs at the mRNA and protein level. The maximal inhibition of protein expression of IL- 6 , TNF- $\alpha$ and iNOS was 46.9, 42.7 and 49.2\% in fibrinogen-stimulated VSMCs, and 50.2, 49.8 and 53.6\% in FDP-stimulated VSMCs, respectively. This suggests that pravastatin has the ability to relieve vascular inflammation via inhibiting the generation of IL-6, TNF- $\alpha$ and iNOS. The results of the present study may aid in further explaining the beneficial effects of pravastatin on atherosclerosis and related cardiovascular diseases. In addition, they suggest that application of pravastatin may be beneficial for prevention of atherosclerosis formation in hyperfibrinogenemia.
\end{abstract}

\section{Introduction}

Inflammation is important in the development and progression of atherosclerosis $(1,2)$. The inflammatory processes are characterized by increased circulating levels of pro-inflammatory cytokines, including interleukin (IL)-1 $\beta$, IL-6, tumor necrosis

Correspondence to: Professor Juntian Liu, Department of Pharmacology, Xi'an Jiaotong University School of Medicine, 76 West Yanta Road, Xi'an, Shaanxi 710061, P.R. China

E-mail: ljt@mail.xjtu.edu.cn

Key words: pravastatin, fibrinogen, inflammatory cytokine, vascular smooth muscle cells, atherosclerosis factor- $\alpha$ (TNF- $\alpha)$ and inducible nitric oxide synthase (iNOS), soluble adhesion molecules, and cytokine-responsive acute phase protein such as C-reactive protein (CRP) $(3,4)$.

Fibrinogen, the acute phase reactant in humans, is derived predominantly from hepatocytes in response to IL-6 and is then secreted into the systemic circulation (5). Recent studies have reported that in addition to its predictive role in determining cardiovascular risk, fibrinogen also exerts a direct pro-inflammatory role on the different vascular cells implicated in atherogenesis (6,7). Fibrinogen stimulates the production of inflammatory cytokines (IL-6, TNF- $\alpha$, IL-1 $\beta$, IL-8 and endothelin-1) in endothelial cells $(7,8)$, macrophages (9), monocytes (10) and neutrophils (11). In addition, fibrinogen participates in the formation of atherosclerosis lesions through promoting platelet aggregation (12), increasing plasma viscosity (13), injuring endothelial cells $(14,15)$, and stimulating migration and proliferation of vascular smooth muscle cells (VSMCs) $(16,17)$. Furthermore, fibrinogen is degraded by plasmin to a series of fibrin degradation products (FDPs), which share similar bioactivities to fibrinogen and also are associated with the progression of atherosclerosis $(17,18)$. Our previous studies showed that fibrinogen and FDP upregulate the expression of CRP, IL-6, TNF- $\alpha$ and iNOS in VSMCs $(19,20)$.

3-Hydroxy-3-methylglutaryl-coenzyme A reductase inhibitors (statins) effectively lower the serum cholesterol level and reduce cardiovascular events and mortality in patients with or without coronary artery disease (21). The beneficial effects of statins have also been characterized by their non-lipid related mechanisms, such as preventing inflammation, improving endothelial function, inhibiting activation of VSMCs, stabilizing atherosclerotic plaques, and preventing thrombosis formation $(21,22)$. Since chronic inflammation in the vessel wall is important in atherogenesis, and hyperfibrinogenemia is associated with cardiovascular disorders, including atherosclerosis, the aim of this study was to observe whether pravastatin regulated fibrinogen- and FDP-induced production of IL-6, TNF- $\alpha$ and iNOS, and to highlight its anti-inflammatory effect and anti-atherosclerotic action.

\section{Materials and methods}

Reagents. Plasminogen-depleted fibrinogen and plasmin were obtained from Calbiochem (Merck, Darmstadt, Germany). 
Fetal bovine serum (FBS) was purchased from Hyclone (Logan, UT, USA). Dulbecco's modified Eagle's medium (DMEM), penicillin and streptomycin were produced by Gibco-BRL (Carlsbad, CA, USA). Pravastatin and thrombin were purchased from Sigma-Aldrich (St. Louis, MO, USA). Rat IL-6 and TNF- $\alpha$ ELISA kits were obtained from Alpha Diagnostics International (San Antonio, TX, USA). Polyclonal rabbit anti-rat iNOS antibody (cat. no. bs-0162R) was provided by Beijing Biosynthesis Biotechnology (Beijing, China). TRIzol reagent kits were provided by Invitrogen Life Technologies (Carlsbad, CA, USA). The Revert Aid ${ }^{\mathrm{TM}}$ First Strand cDNA Synthesis kit was obtained from Fermentas (St. Leon-Rot, Germany). Agarose gels were from Spanish Biochemicals Corp. (Madrid, Spain).

Culture of rat VSMCs. Male Sprague-Dawley rats $(\mathrm{n}=12$; age, 2-3 months; weight, 100-150 g) were obtained from the Laboratory Animal Center of Xi'an Jiaotong University School of Medicine (Xi'an, China). VSMCs were prepared from the thoracic aorta of using the explant method as described previously (23). Briefly, rats were anesthetized with intraperitoneal injection of sodium pentobarbital $(30 \mathrm{mg} / \mathrm{kg}$; Sigma-Aldrich). The thoracic aorta was removed and freed of connective tissue and adherent fat. The endothelial cell layer of the intima was removed mechanically, and the aortic artery was cut into sections of $\sim 3 \mathrm{~mm}$. These were then placed in DMEM supplemented with $10 \%$ FBS, $100 \mathrm{U} / \mathrm{ml}$ penicillin, $100 \mu \mathrm{g} / \mathrm{ml}$ streptomycin in a humidified atmosphere of $5 \% \mathrm{CO}_{2}$ and $95 \%$ air at $37^{\circ} \mathrm{C}$ until VSMCs exhibited a typical 'hill and valley' growth pattern. Finally, VSMCs were identified with the morphological examination, and showed $99 \%$ purity as estimated with the immunocytochemical staining for $\alpha$-actin. The cells were observed using an optical microscope (Eclipse E600; Nikon Corporation, Tokyo, Japan) and the positive ratio of immunocytochemical staining for $\alpha$-actin was analyzed with Image-Pro Plus 5.0 software (Media Cybernetics Inc., Rockville, MD, USA). The cells were passaged by brief trypsinization (MP Biomedicals, Santa Ana, CA, USA), and the cells between passages 3 and 8 were used for the experiments. When the cells were grown to confluence, they were starved for $24 \mathrm{~h}$ in serum-free medium prior to the experiments. All experimental procedures were performed in accordance with the international, national and institutional rules, and approved by the Institutional Animal Care Committee of Xi'an Jiaotong University (Xi'an, China).

Experimental protocols. VSMCs were cultured in 6-well plates at a density of $5 \times 10^{6}$ cells/well. When cells had been starved for $24 \mathrm{~h}$ in the serum-free medium, the cells were divided into the following groups: Control, cells treated with fibrinogen or FDP, and cells treated with fibrinogen or FDP with pravastatin $(10,30$ or $100 \mu \mathrm{mol} / \mathrm{l})$. Following pretreatment with pravastatin for $30 \mathrm{~min}$, the cells were stimulated with $5 \mu \mathrm{mol} / 1$ fibrinogen for $9 \mathrm{~h}$, or $1 \mathrm{ml}$ FDP diluted in $30 \mathrm{ml}$ physiological saline (1/30 FDP) for $3 \mathrm{~h}$, as previously described by Naito et al (17). Then, the supernatant was collected. IL-6 and TNF- $\alpha$ levels were determined using an ELISA, and iNOS protein expression was detected with immunofluorescence. mRNA expression of IL-6, TNF- $\alpha$ and iNOS were determined by reverse transcription-polymerase chain reaction (RT-PCR).
Preparation of FDP. About 6.3 units of human thrombin were mixed with $3 \mathrm{ml}$ fibrinogen $(50 \mu \mathrm{mol} / \mathrm{l})$, and incubated overnight at $37^{\circ} \mathrm{C}$. The formed clots were homogenized for $10 \mathrm{sec}$, and centrifuged at $600 \mathrm{x}$ g for $10 \mathrm{~min}$. Then, the supernatant was removed, and the clots were washed three times with physiological saline. Digestion of the clots was conducted in Tris-buffered saline containing physiological levels of calcium ( $10 \mathrm{mmol} / 1 \mathrm{Tris}, 100 \mathrm{mmol} / 1 \mathrm{NaCl}$ and $2.5 \mathrm{mmol} / \mathrm{C} \mathrm{CaCl}_{2}, \mathrm{pH}$ ). The clotted fibrin was suspended in $5 \mathrm{ml}$ buffer, and 2 units of human plasmin were added to form FDP. Subsequently. the samples were placed on a rotator in a $37^{\circ} \mathrm{C}$ incubator for $48 \mathrm{~h}$, and sterilized by passing the samples through a $0.22-\mu \mathrm{m}$ pore sterilization filter (17). Finally, the samples containing FDP were diluted with physiological saline. FDP concentrations were expressed as the diluted proportion.

ELISA. VSMCs were cultured in 6-well plates at a density of $5 \times 10^{6}$ cells/well. The cells were stimulated with fibrinogen (5 $\mu \mathrm{mol} / \mathrm{l})$ or FDP $(1 / 30)$ for the indicated time after pretreatment for $30 \mathrm{~min}$ with pravastatin at 10,30 or $100 \mu \mathrm{mol} / 1$. Then, the supernatant was collected for assay of IL- 6 and TNF- $\alpha$ by ELISA kits specific for rat IL- 6 and TNF- $\alpha$ according to the manufacturer's instructions.

$R T-P C R$. Total RNA was extracted and complementary DNA (cDNA) was synthesized from $1 \mu \mathrm{g}$ of total RNA with random hexamer primers using Revert Aid $^{\text {TM }}$ First Strand cDNA Synthesis kit according to the manufacturer's instructions. PCR amplification was performed through 35 cycles at $94^{\circ} \mathrm{C}$ for $30 \mathrm{sec}, 54^{\circ} \mathrm{C}$ for $30 \mathrm{sec}$, and $72^{\circ} \mathrm{C}$ for $30 \mathrm{sec}$, and the final extension of PCR products was performed for $5 \mathrm{~min}$ at $72^{\circ} \mathrm{C}$. Primers for rat IL- $6, \mathrm{TNF}-\alpha$, iNOS and glyceraldehyde-3-phosphate dehydrogenase (GAPDH) were designed with Beacon designer 4.0 (Palo Alto, CA, USA) (Table I). GAPDH was used as an internal control. The samples were run in triplicate. Equal volumes of the reaction mixture from each sample were loaded on a $2 \%$ TAE agarose gel (Spanish Biochemicals Corp., Madrid, Spain) containing ethidium bromide, and resolved by electrophoresis. Images were digitally captured using a gel analysis system (JS-680D; Shanghai Peiqing Science \& Technology Co., Ltd., Shanghai, China), and band intensity was analyzed using Gel Pro Analyzer software, Version 4.0 (Media Cybernetics., Inc., Rockville, MD, USA). The relative amount of each mRNA was normalized to the housekeeping gene (GADPH) mRNA.

Immunofluorescent analysis of iNOS. VSMCs were plated on cover slips in 6-well plates until $90 \%$ confluency. Then, the treated cells were fixed with $4 \%$ formaldehyde in phosphate-buffered saline (PBS) for $15 \mathrm{~min}$. The cell membrane was permeabilized with $0.2 \%$ Triton X-100-PBS (Amresco, LLC, Solon, OH, USA) for $20 \mathrm{~min}$, and the non-specific binding sites were blocked with $10 \%$ goat serum. Following pretreatment with rabbit anti-rat iNOS antibody (1:200 diluted in PBS) overnight at $4^{\circ} \mathrm{C}$, the cells were washed three times with phosphate-buffered saline, and incubated with the secondary antibodies conjugated to fluorescein isothiocyanate for $15 \mathrm{~min}$ at room temperature. Finally, the immunolabeled cells were observed under a fluorescent microscope (BX-51 Olympus, Tokyo, Japan), and fluorescent intensity of iNOS was 
Table I. Primer sequence used for RT-PCR analysis.

\begin{tabular}{llr}
\hline Gene & \multicolumn{1}{c}{ Primer sequence } & Accession numbe \\
\hline IL-6 & 5'-TCCAGCCAGTTGCCTTCTTG-3' & NM_012589 \\
& 5'-AGCCACTCCTTCTGTGACTC-3' & \\
TNF- $\alpha$ & 5'-CCAGAACTCCAGGCGGTGTC-3' & NM_012675 \\
iNOS & 5'-GGCTACGGGCTTGTCACTCG-3' & \\
& 5'-GGAAGAGACGCACAGGCAGAG-3' & NM_012611 \\
GAPDH & 5'-GCAGGCACACGCAATGATGG-3' & \\
& 5'-GCCTTCTCCATGGTGGTGAA-3' & NM_017008 \\
& 5'-GGTCGGTGTGAACGGATTTG-3'
\end{tabular}

IL, interleukin; TNF, tumor necrosis factor; iNOS, inducible nitric oxide synthase.

A

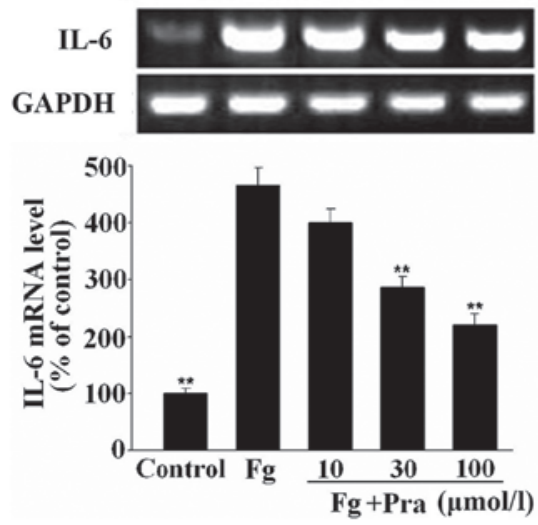

B

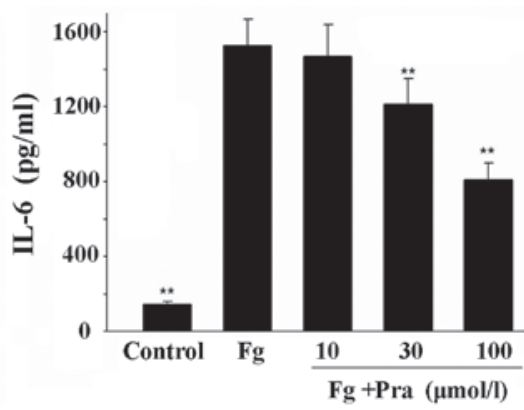

Figure 1. Effect of Pra on Fg-induced expression of IL-6 in VSMCs. VSMCs were stimulated with $5 \mu \mathrm{mol} / \mathrm{l} \mathrm{Fg}$ for $9 \mathrm{~h}$ after pretreatment for 30 min with different concentrations of Pra. Then, (A) mRNA and (B) protein expression of IL- 6 were determined by reverse transcription-quantitative polymerase chain reaction and ELISA, respectively. Values from three independent experiments are expressed as the mean \pm standard deviation. ${ }^{* *} \mathrm{P}<0.01 \mathrm{vs}$. Fg. Pra, pravastatin; IL, interleukin; VSMCs, Vascular smooth muscle cells; Fg, fibrinogen.

detected and analyzed with Image-Pro Plus software (Media Cybernetics., Inc., Rockville, MD, USA). Data were expressed as relative to the control.

Statistical analysis. Data are expressed as the mean \pm standard deviation. The experiments were repeated three times, and the differences between means were examined for statistical significance $(\mathrm{P}<0.05)$ by one-way analysis of variance followed by Fisher's exact test. SPSS 13.0 (SPSS, Inc., Chicago, IL, USA) was used for all statistical analyses.

\section{Results}

Pravastatin inhibits fibrinogen- and FDP-induced IL-6 expression in VSMCs. As shown in Figs. 1 and 2, mRNA and protein expression of IL-6 was low in the unstimulated VSMCs. However, mRNA and protein expression of IL-6 was significantly increased following stimulation of VSMCs with fibrinogen or FDP ( $\mathrm{P}<0.01$ vs. control). However, pravastatin dose-dependently suppressed fibrinogen- and FDP-stimulated IL-6 expression in VSMCs in protein and mRNA levels $(\mathrm{P}<0.01$ vs. fibrinogen or FDP alone). The inhibitory rates in protein levels were 3.7,20.7 and 46.9\% in fibrinogen-stimulated
VSMCs, and were 13.1, 27.9 and 50.2\% in FDP-stimulated VSMCs with the increase of pravastatin concentration.

Pravastatin attenuates fibrinogen- and FDP-induced TNF- $\alpha$ expression in VSMCs. As observed in Figs. 3 and 4, fibrinogen and FDP produced a significant increase in the mRNA and protein expression of TNF- $\alpha$ in VSMCs ( $\mathrm{P}<0.01$ vs. control), while pretreatment of the cells with pravastatin inhibited fibrinogen- and FDP-induced mRNA and protein expression of TNF- $\alpha$ in a concentration-dependent manner $(\mathrm{P}<0.01$ vs. fibrinogen or FDP alone). The maximal inhibition of fibrinogen- and FDP-induced TNF- $\alpha$ protein expression was 42.7 and $49.8 \%$, respectively.

Pravastatin reduces fibrinogen- and FDP-stimulated iNOS expression in VSMCs. The results shown in Figs. 5 and 6 indicate that mRNA and protein expression of iNOS in VSMCs was significantly enhanced after exposure of the cells to the same concentration of fibrinogen and FDP $(\mathrm{P}<0.05$ vs. control). However, pretreatment of the cells with pravastatin antagonized the stimulatory effect of fibrinogen and FDP on mRNA and protein expression of iNOS in a dose-dependent manner ( $\mathrm{P}<0.05$ or $\mathrm{P}<0.01$ vs. fibrinogen or FDP alone). The 


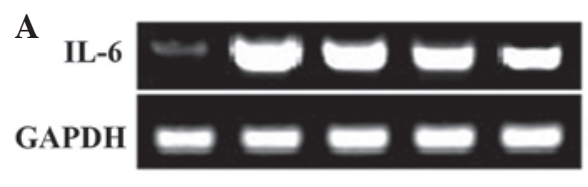

B
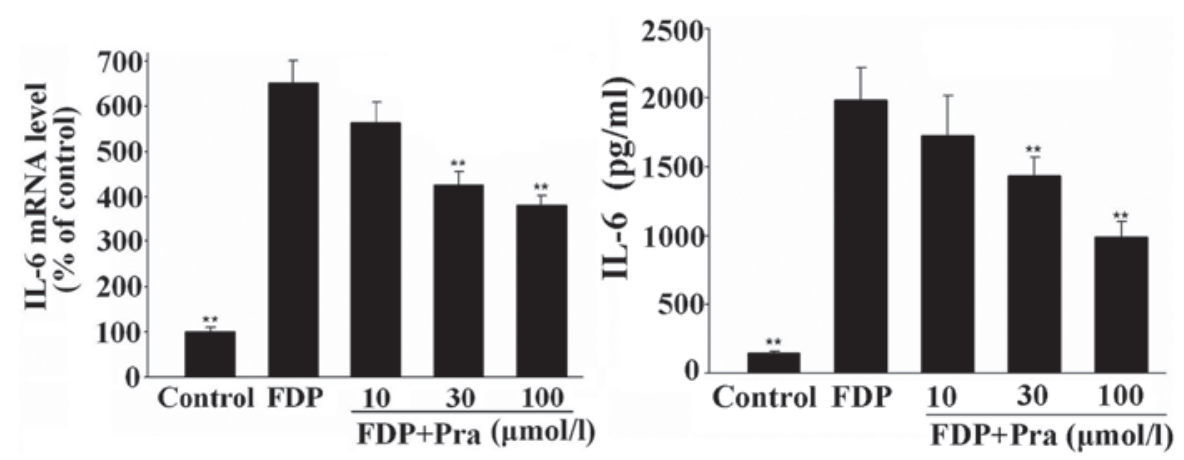

Figure 2. Effect of Pra on FDP-induced expression of IL-6 in VSMCs. VSMCs were stimulated with 1/30 FDP for $3 \mathrm{~h}$ after pretreatment for 30 min with different concentrations of Pra. Then, (A) mRNA (B) protein expression of IL-6 were determined by rverse transcription-polymerase chain reaction and ELISA, respectively. Values from three independent experiments are expressed as the mean \pm standard deviation. ${ }^{* *} \mathrm{P}<0.01$ vs. FDP. Pra, pravastatin; FDP, fibrin degradation products; IL, interleukin; VSMCs, vascular smooth muscle cells.

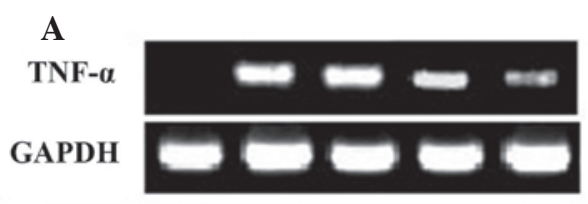

B
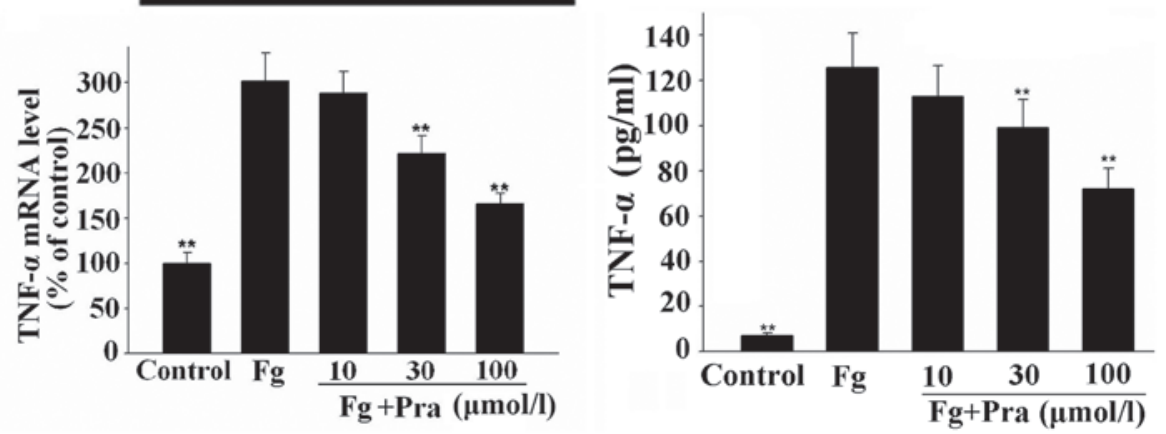

Figure 3. Effect of Pra on Fg-stimulated expression of TNF- $\alpha$ in VSMCs. VSMCs were stimulated with $5 \mu \mathrm{mol} / 1 \mathrm{Fg}$ for $9 \mathrm{~h}$ after pretreatment for $30 \mathrm{~min}$ with the different concentrations of Pra. Then, (A) mRNA and (B) protein expression of TNF- $\alpha$ were determined by reverse transcription-polymerase chain reaction and ELISA, respectively. Values from three independent experiments are expressed as the mean \pm standard deviation. ${ }^{* *} \mathrm{P}<0.01$ vs. Fg. Pra, pravastatin; Fg, fibrinogen; TNF- $\alpha$, tumor necrosis factor- $\alpha$; VSMCs, vascular smooth muscle cells.

A
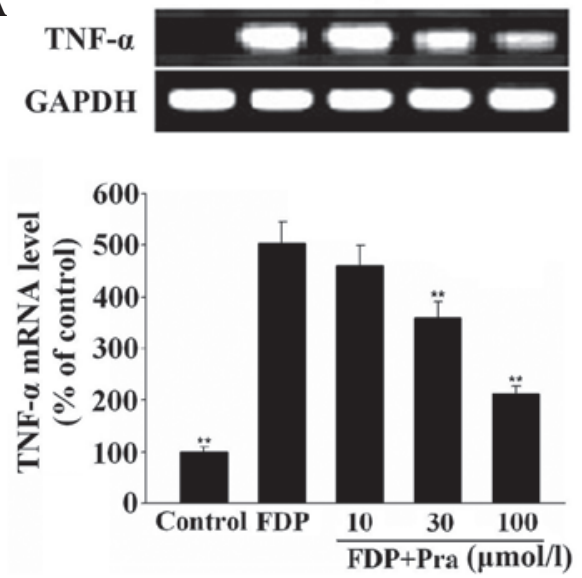

B

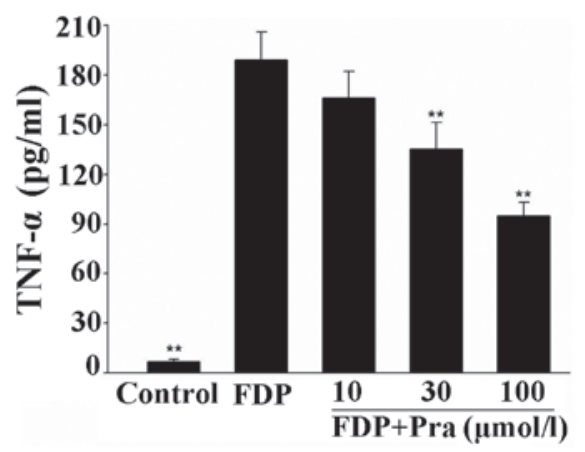

Figure 4. Effect of Pra on FDP-stimulated expression of TNF- $\alpha$ in VSMCs. VSMCs were stimulated with 1/30 FDP for $3 \mathrm{~h}$ after pretreatment for 30 min with different concentrations of Pra. Then, (A) mRNA and (B) protein expression of TNF- $\alpha$ were determined by reverse transcription-polymerase chain reaction and ELISA, respectively. Values from three independent experiments are expressed as the mean \pm standard deviation. * P $<0.01$ vs. FDP. Pra, pravastatin; FDP, fibrin degradation products; TNF- $\alpha$, tumor necrosis factor- $\alpha$; VSMCs, vascular smooth muscle cells. 


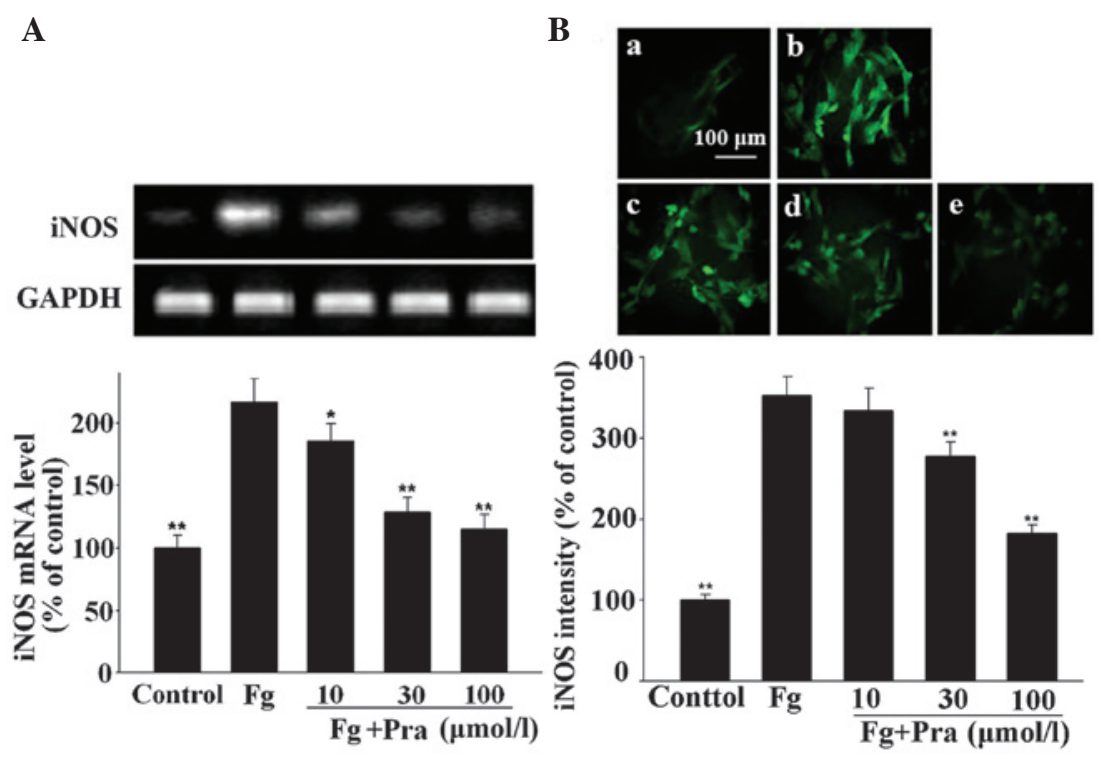

Figure 5. Effect of Pra on Fg-induced expression of iNOS in VSMCs. VSMCs were stimulated with $5 \mu \mathrm{mol} / \mathrm{l} \mathrm{Fg}$ for $9 \mathrm{~h}$ after pretreatment for 30 min with different concentrations of Pra. Then, mRNA and protein expression of iNOS was determined by reverse transcription-polymerase chain reaction and immunofluorescence, respectively. (A) mRNA expression of iNOS. Protein expression of iNOS in (Ba) control, (Bb) Fg alone, (Bc) Fg+10 $\mu \mathrm{mol} / 1 \mathrm{Pra}$, (Bd) $\mathrm{Fg}+30 \mu \mathrm{mol} / 1 \mathrm{Pra}$ and (Be) $\mathrm{Fg}+100 \mu \mathrm{mol} / 1 \mathrm{Pra}$. Values from three independent experiments are expressed as the mean \pm standard deviation. "P $<0.05$ and ${ }^{* *} \mathrm{P}<0.01$ vs. Fg. Scale bar, $100 \mu \mathrm{m}$. Pra, pravastatin; Fg, fibrinogen; iNOS, inducible nitric oxide synthase; VSMCs, vascular smooth muscle cells.
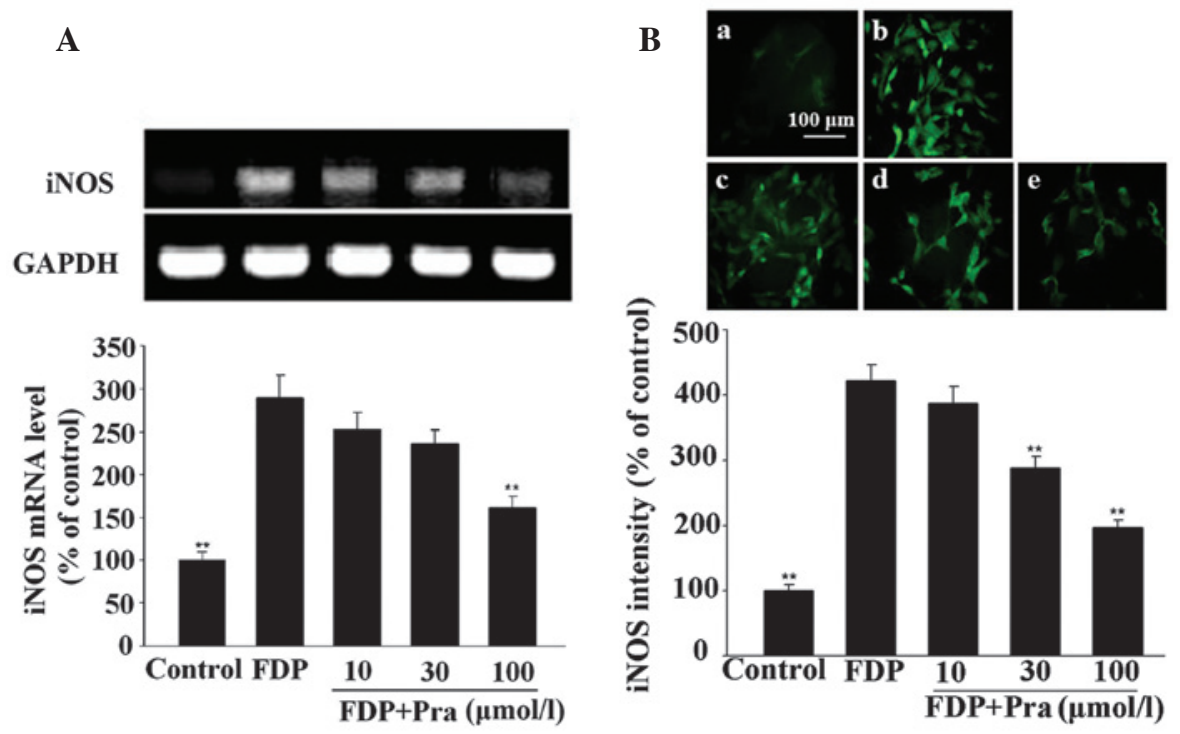

Figure 6. Effect of Pra on FDP-induced expression of iNOS in VSMCs. VSMCs were stimulated with 1/30 FDP for $3 \mathrm{~h}$ after pretreatment for 30 min with the different concentrations of Pra. Then, mRNA and protein expression of iNOS was determined by reverse transcription-polymerase chain reaction and immunofluorescence, respectively. (A) iNOS mRNA expression. iNOS protein expression in (Ba) control, (Bb) FDP alone, (Bc) FDP+10 $\mu$ mol/1 Pra, (Bd) FDP $+30 \mu \mathrm{mol} / 1$ Pra and (Be) FDP+100 $\mu \mathrm{mol} / 1$ Pra. Values from three independent experiments are expressed as the means \pm standard deviation. ${ }^{* * *} \mathrm{P}<0.01$ vs. FDP. Scale bar, $100 \mu \mathrm{m}$. Pra, pravastatin; FDP, fibrin degradation products; iNOS, inducible nitric oxide synthase; VSMCs, vascular smooth muscle cells.

maximal inhibition reached $49.2 \%$ for fibrinogen-induced iNOS protein expression and $53.6 \%$ for FDP-induced iNOS protein expression.

\section{Discussion}

Atherosclerosis is considered to be a chronic inflammatory disease that leads to a number of cardiovascular diseases (CVDs). Statins have been demonstrated to decrease cardiovascular events through their pleiotropic properties, including anti-inflammatory action (24). However, the precise mechanisms by which statins inhibit inflammatory responses remain unclear.

VSMCs are the major players implicated in atherogenesis. Migration and proliferation of VSMCs are the critical events in the initiation and progression of atherosclerosis as well as in the inflammatory processes $(6,2)$. IL- 6 and TNF- $\alpha$ are the important pro-inflammatory cytokines involved in 
atherogenesis, which stimulate the release of other inflammatory mediators, increase expression of adhesion molecules in endothelial cells, promote release of various chemokines to recruit monocytes to the injury site and enhance their adhesiveness to endothelium $(25,26)$. A clinical study suggests that high serum levels of IL-6 and TNF- $\alpha$ is associated with a worse prognosis in patients after acute myocardial infarction (27).

It is known that iNOS exists in human atherosclerotic lesions as several factors present in atherosclerotic plaques, such as TNF- $\alpha$, IL- 1 and $\gamma$-interferon, are able to induce iNOS expression in VSMCs. High iNOS activity produces large quantities of NO, which may lead to cellular damage, inflammation, apoptosis and peroxynitrite formation. Furthermore, peroxynitrite may cause oxidative damage to endothelial cells and VSMCs, and therefore is important in the pathology of atherosclerosis (28-30).

Although the role of fibrinogen in the clotting cascade has been well defined, its role in the inflammatory response is less well understood. It has long been demonstrated that fibrinogen and its fragments are incorporated into atherosclerotic plaques as the plaques develop (31). Fibrinogen is also converted into a fibrin matrix at the site of inflammation, and fibrin(ogen) deposition may directly participate in the inflammatory response by providing a scaffold for inflammatory cell adhesion and migration, and for subsequent remodeling of the tissue with extracellular matrix (32). Our previous studies found that fibrinogen and FDP are able to produce a pro-inflammatory effect on VSMCs via stimulating the generation of CRP, IL-6, TNF- $\alpha$ and iNOS, which suggests a novel mechanism involving fibrinogen in atherogenesis $(19,20)$.

In view of the pro-inflammatory effect of fibrinogen on VSMCs, which is involved in its pro-atherosclerotic process, the inhibitory effect of pravastatin on fibrinogen- and FDP-stimulated generation of inflammatory cytokines, such as IL-6, TNF- $\alpha$ and iNOS, was observed in VSMCs. The results showed that pravastatin at the concentrations used in the present study significantly inhibited fibrinogen- and FDP-stimulated expression of IL-6, TNF- $\alpha$ and iNOS in VSMCs at the mRNA and protein leves, suggesting that pravastatin is able to exert an anti-inflammatory effect via decreasing fibrinogen- and FDP-induced expression of IL-6, TNF- $\alpha$ and iNOS in VSMCs.

Our previous study demonstrated that lovastatin reduces nuclear factor- $\mathrm{\kappa B}$ activation induced by CRP in human vascular endothelial cells (33), and Han et al in turn demonstrated that simvastatin inhibits angiotensin II-induced CRP expression in human aortic endothelial cells through interfering with $\mathrm{AT}_{1}$-reactive oxygen species-mitogen activated protein kinase (MAPK) signaling pathway (unpublished data). The MAPK signal pathway mediates the inflammatory response induced by inflammatory cytokines in the atherogenesis-related cells (34-37). Thus, it was inferred that pravastatin, analogous to lovastatin and simvastatin, reduces fibrinogen- and FDP-stimulated generation of IL-6, TNF- $\alpha$ and iNOS in VSMCs possibly by inhibiting the MAPK signaling pathway. Further studies are required to characterize the mechanisms responsible for the inhibitory effect of pravastatin.

In conclusion, the present results demonstrate that pravastatin is able to inhibit fibrinogen- and FDP-stimulated generation of IL-6, TNF- $\alpha$ and iNOS in VSMCs thus relieving the inflammatory response in the vessel wall involved in atherogenesis. This may aid in further explaining the beneficial effects of pravastatin on atherosclerosis and CVDs. It also suggests that application of pravastatin may be beneficial for the prevention of atherosclerosis in hyperfibrinogenemia.

\section{Acknowledgements}

This study was supported by the Doctoral Fund of the Ministry of Education of China (grant no. 20100201110053).

\section{References}

1. Hansson GK: Inflammation, atherosclerosis and coronary artery disease. N Engl J Med 352: 1685-1695, 2005.

2. Libby P: Inflammation in atherosclerosis. Nature 420: 868-874, 2002.

3. Bermudez EA, Rifai N, Buring J, Manson JE and Ridker PM: Interrelationships among circulating interleukin-6, C-reactive protein and traditional cardiovascular risk factors in women. Arterioscler Thromb Vasc Biol 22: 1668-1673, 2002.

4. Lind L: Circulating markers of inflammation and atherosclerosis. Atherosclerosis 169: 203-214, 2003.

5. Huber SA, Sakkinen P, Conze D, Hardin N and Tracy R: Interleukin-6 exacerbates early atherosclerosis in mice. Arterioscler Thromb Vasc Biol 19: 2364-2367, 1999.

6. Ross R: Atherosclerosis-an inflammatory disease. N Engl J Med 340: 115-126, 1999.

7. Lominadze D, Dean WL, Tyagi SC and Roberts AM: Mechanisms of fibrinogen-induced microvascular dysfunction during cardiovascular disease. Acta Physiol (Oxf) 198: 1-13, 2010.

8. Sen U, Tyagi N, Patibandla PK, Dean WL, Tyagi SC, Roberts AM and Lominadze D: Fibrinogen-induced endothelin-1 production from endothelial cells. Am J Physiol Cell Physiol 296: C840-C847, 2009.

9. Szaba FM and Smiley ST: Roles for thrombin and fibrin(ogen) in cytokine/chemokine production and macrophage adhesion in vivo. Blood 99: 1053-1059, 2002.

10. Robson SC, Shephard EG and Kirsch RE: Fibrin degradation product D-dimer induces the synthesis and release of biologically active IL-lbeta, IL-6 and plasminogen activator inhibitors from monocytes in vitro. Br J Haematol 86: 322-326, 1994.

11. Kuhns DB, Nelson EL, Alvord WG and Gallin JI: Fibrinogen induces IL-8 synthesis in human neutrophils stimulated with formyl-methionyl-leucyl-phenylalanine or leukotriene B(4). J Immunol 167: 2869-2878, 2001.

12. Tsakadze NL, Zhao Z and D'Souza SE: Interaction of intercellular adhesion molecule-1 with fibrinogen. Trends Cardiovasc Med 12: 101-108, 2002.

13. Mosesson MW: Fibrinogen and fibrin structure and functions. J Thromb Haemost 3: 1894-1904, 2005.

14. Tyagi N, Roberts AM, Dean WL, Tyagi SC and Lominadze D: Fibrinogen induces endothelial cell permeability. Mol Cell Biochem 307: 13-22, 2008.

15. Patibandla PK, Tyagi N, Dean WL, Tyagi SC, Roberts AM and Lominadze D: Fibrinogen induces alterations of endothelial cell tight junction proteins. J Cell Physiol 221: 195-203, 2009.

16. Rauch BH, Müschenborn B, Braun M, Weber AA and Schrör K: ICAM-1 and p38 MAPK mediate fibrinogen-induced migration of human vascular smooth muscle cells. Eur J Pharmacol 577: 54-57, 2007.

17. Naito M, Stirk CM, Smith EB and Thompson WD: Smooth muscle cell outgrowth stimulated by fibrin degradation products: The potential role of fibrin fragment $\mathrm{E}$ in restenosis and atherogenesis. Thromb Res 98: 165-174, 2000.

18. Hicks RC, Golledge J, Mir-Hasseine R and Powell JT: Vasoactive effects of fibrinogen on saphenous vein. Nature 379: 818-820, 1996.

19. Guo F, Liu JT, Wang CJ, Liu N and Lu PP: Fibrinogen, fibrin and FDP induce C-reactive protein generation in rat vascular smooth muscle cells: Pro-inflammatory effect on atherosclerosis. Biochem Biophy Res Commun 390: 942-946, 2009.

20. Lu PP, Liu JT, Liu N, Guo F, Ji YY and Pang X: Pro-inflammatory effect of fibrinogen and FDP on vascular smooth muscle cells by IL-6, TNF- $\alpha$ and iNOS. Life Sci 88: 839-845, 2011. 
21. Veillard NR and Mach F: Statins: The new aspirin? Cell Mol Life Sci 59: 1771-1786, 2002.

22. Gaugler MH, Vereycken-Holler V, Squiban C, Vandamme M, Vozenin-Brotons MC and Benderitter M: Pravastatin limits endothelial activation after irradiation and decreases the resulting inflammatory and thrombotic responses. Radiat Res 163: 479-487, 2005.

23. Hadrava V, Tremblay $\mathrm{J}$ and Hamet P: Abnormalities in growth characteristics of aortic smooth muscle cells in spontaneously hypertensive rats. Hypertension 13: 589-597, 1989.

24. Takemoto MandLiao JK: Pleiotropic effects of 3-hydroxy-3-methylglutaryl coenzyme a reductase inhibitors. Arterioscler Thromb Vasc Biol 21: 1712-1719, 2001

25. Tedgui A and Mallat Z: Cytokines in atherosclewrosis: Pathogenic and regulatory pathways. Physiol Rev 86: 515-581, 2006.

26. Yudkin JS, Kumari M, Humphries SE and Mohamed-Ali V: Inflammation, obesity, stress and coronary heart disease: Is interleukin-6 the link? Atherosclerosis 148: 209-214, 2000.

27. Kosmala W, Przewlocka-Kosmala M and Mazurek W Proinflammatory cytokines and myocardial viability in patients after acute myocardial infarction. Int J Cardiol 101: 449-456, 2005.

28. Buttery LD, Springall DR, Chester AH, Evans TJ, Standfield EN, Parums DV, Yacoub MH and Polak JM: Inducible nitric oxide synthase is present within human atherosclerotic lesions and promotes the formation and activity of peroxynitrite. Lab Invest 75: 77-85, 1996.

29. Luoma JS, Strålin P, Marklund SL, Hiltunen TP, Särkioja T and Ylä-Herttuala S: Expression of extracellular SOD and iNOS in macrophages and smooth muscle cells in human and rabbit atherosclerotic lesions: Colocalization with epitopes characteristic of oxidized LDL and peroxynitrite-modified proteins. Arterioscler Thromb Vasc Biol 18: 157-167, 1998.
30. Radomski MW and Salas E: Nitric oxide-biological mediator modulator and factor of injury: its role in the pathogenesis of atherosclerosis. Atherosclerosis 118 (Suppl): S69-S80, 1995.

31. Smith EB, Thompson WD, Crosbie L and Stirk CM: Fibrinogen/fibrin in atherogenesis. Eur J Epidemiol 8 (Suppl 1): 83-87, 1992.

32. Perez RL and Roman J: Fibrin enhances the expression of IL-lbeta by human peripheral blood mononuclear cells. Implications in pulmonary inflammation. J Immunol 154: 1879-1887, 1995.

33. Lin R, Liu J, Peng N, Yang G, Gan W and Wang W: Lovastatin reduces nuclear factor kappaB activation induced by C-reactive protein in human vascular endothelial cells. Biol Pharm Bull 28: 1630-1634, 2005.

34. Peng N, Liu JT, Gao DF, Lin R and Li R: Angiotensin II-induced $\mathrm{C}$-reactive protein generation: Inflammatory role of vascular smooth muscle cells in atherosclerosis. Atherosclerosis 193: 292-298, 2007.

35. Wang C, Liu J, Guo F, Ji Y and Liu N: Endothelin-1 induces the expression of C-reactive protein in rat vascular smooth muscle cells. Biochem Biophys Res Commun 389: 537-542, 2009.

36. Han C, Liu J, Liu X and Li M: Angiotensin II induces C-reactive protein expression through ERK1/2 and JNK signaling in human aortic endothelial cells. Atherosclerosis 212: 206-212, 2010.

37. Li M, Liu J, Han C, Wang B, Pang X and Mao J: Angiotensin II induces the expression of c-reactive protein via MAPK-dependent signal pathway in U937 macrophages. Cell Physiol Biochem 27: 63-70, 2011 